\title{
Histologic grading of the tumor/tissue interface to predict lymph node metastasis in squamous cell carcinoma of the tongue
}

\section{Histologiczne stopnie złośliwości tkanki nowotworowej a predykcja przerzutowania do węzłów chłonnych w raku płaskonabłonkowym języka}

\author{
Ranjith Shetty ${ }^{A-F}$ \\ A - research concept and design; B - collection and/or assembly of data; $C$ - data analysis and interpretation; \\ $D$ - writing the article; $E$ - critical revision of the article; $F$ - final approval of the article
}

Department of Oral Pathology and Microbiology, A.B. Shetty Memorial Institute of Dental Sciences, NITTE (Deemed to be University), Mangalore, India

\section{Address for correspondence \\ Ranjith Shetty \\ E-mail: drranjithshetty0323@gmail.com \\ Funding sources \\ None declared \\ Conflict of interest \\ None declared \\ Received on December 16, 2019 \\ Reviewed on January 24, 2020 \\ Accepted on March 31, 2020}

Published online on September 30, 2020

Cite as

Shetty R. Histologic grading of the tumor/tissue interface to predict lymph node metastasis in squamous cell carcinoma of the tongue. Dent Med Probl. 2020;57(3):233-238 doi:10.17219/dmp/119937

DOI

$10.17219 / \mathrm{dmp} / 119937$

Copyright

○) 2020 by Wroclaw Medical University

This is an article distributed under the terms of the

Creative Commons Attribution 3.0 Unported License (CC BY 3.0)

(https://creativecommons.org/licenses/by/3.0/).

\begin{abstract}
Background. The invasive front is presumed to contain the most aggressive subpopulation of tumor cells that ultimately invade, spread locally and metastasize. Studying the histopathological grading of the tumor/tissue interface at the invasive front may help in developing the treatment plan.

Objectives. The aim of this study was to check the reliability of the tumor/tissue interface in predicting lymph node metastasis in oral squamous cell carcinoma (OSCC) of the tongue by evaluating the following: the histopathological grading of hematoxylin and eosin (H\&E)-stained excision biopsy specimens according to the modified version of Broder's classification system; and the invasive tumor front (ITF) with the modified version of Bryne's grading system. The study also aimed at studying the lymph nodes for metastases and comparing these histopathological grading systems and lymph node metastases.
\end{abstract}

Material and methods. All retrospective and prospective cases from the archives of the Department of Oral Pathology and Microbiology of the A.B. Shetty Memorial Institute of Dental Sciences (ABSMIDS), NITTE University in Mangalore, India, collected during the period from 2012 to 2014 were considered for histopathological grading.

Results. This study found a significant association between the modified version of Bryne's ITF grading system and lymph node metastases whereas the widely used modified version of Broder's classification failed to show any statistical significance. Only the multifactorial malignancy grading of the deep invasive margins of OSCC proved to be of high prognostic value.

Conclusions. The study found that the degree of keratinization, nuclear polymorphism, the pattern of invasion, and the host response showed significant variation at the invasive front of the tumor as compared to superficial parts, which makes Bryne's grading system more reliable than Broder's grading system.

Key words: lymph node metastasis, oral squamous cell carcinoma of the tongue, Broder's grading, Bryne's grading, invasive tumor front

Słowa kluczowe: przerzutowanie do węztów chłonnych, rak płaskonabłonkowy języka, stopniowanie złośliwości wg Brodera, stopniowanie złośliwości wg Bryne'a, inwazyjny front raka 


\section{Introduction}

Among cancers affecting oral sites, oral squamous cell carcinoma (OSCC) of the tongue is known to exist as a biologically distinct entity. Oral squamous cell carcinoma of the tongue is considered severe, as it is associated with high rates of metastasis. ${ }^{1}$ It has been estimated that approx. $20 \%$ of squamous cell carcinomas (SCCs) that occur in the oral cavity are believed to emerge from the tongue, and that $75 \%$ of the tongue SCCs arise from the ventrolateral aspect of the mid and posterior tongue. This could be due to the accumulation of carcinogens. In spite of the fact that patients as well as physicians have easy access to the tongue, the malignancy usually presents late and is also painless, so it is often ignored by patients. Gradually, it presents as an ulcer that is non-healing and demonstrates growth over time. ${ }^{2}$ The early identification and treatment of OSCC is most important in reducing the mortality and morbidity related to this devastating disease. ${ }^{3}$ During diagnosis, nodal metastasis is said to be more common $(37-58 \%)$ in the case of the tongue than any other site in the oral cavity. The reason could be the extensive lymphatic drainage of the tongue. Therefore, the reported complaint in these cases may be a neck mass. ${ }^{2}$ Lymph node metastases are most likely to be present in head and neck cancers. ${ }^{3}$ As a result, in the case of cervical node metastases, there is a chance of a decrease in the survival rate by $50 \%$ and an increase in distant metastases.

Histologic grading systems have been devised by many researchers to study the nature of oral carcinoma. Based on its biological behavior, OSCC is differentiated as well-differentiated, moderate or poorly differentiated. The quantitative grading of cancer was primarily developed by Broder in 1920. Broder's classification system for grading a tumor is a classic tool in pathology of documented prognostic value. ${ }^{4,5}$

The invasive front is presumed to contain the most aggressive subpopulation of tumor cells that ultimately invade, spread locally and metastasize. Several events occur at the molecular level, such as the addition or removal of adhesion molecules, the secretion of proteolytic enzymes, and increases in the proliferation of cells and angiogenesis at the tumor/host interface of the invasive front. Hence, histopathological grading at the tumor/tissue interface at the invasive front is necessary and may help in preparing the treatment plan. ${ }^{6}$ This study is an attempt to determine the efficacy of the modification of Broder's grading system and the modification of Byrne's invasive tumor front (ITF) grading system in assessing tumor biology, and their role in predicting lymph node metastases in OSCC of the tongue.

\section{Material and methods}

\section{Source of data}

This study was approved by the Ethics Committee of the A.B. Shetty Memorial Institute of Dental Sciences (ABSMIDS), NITTE (Deemed to be University) in Mangalore, India (ABSM/EC/52/2012). From among the retrospective as well as prospective cases registered from November 2012 to August 2014, 62 cases were selected, of which a total of 30 cases that met the inclusion criteria were included in the study: the cases of OSCC of the tongue diagnosed by excision biopsy and histopathology with radical neck dissection, the archival formalin-fixed and paraffin-embedded representative samples of deep margins with an adequate connective tissue stroma, and cases that were available with sufficient clinical data. The cases of OSCC other than regarding the tongue or without radical neck dissection were excluded. The formalin-fixed excision biopsy specimens of OSCC of the tongue treated with radical neck dissection were collected from the archives of the ABSMIDS Department of Oral Pathology and Microbiology. The cases submitted during the study period were also considered.

\section{Data collection technique}

Histological grading was done on routine 3-5-micrometer-thick sections, stained with Harris hematoxylin and eosin (H\&E) and examined under light microscopy. The observers were blinded to the lymph node status. The main slide containing the whole thickness with an adequate connective tissue stroma of the tumor was taken for grading in each case. Each tumor was graded according to the modification of Broder's grading system ${ }^{7}$ and the modification of Bryne's ITF grading. ${ }^{8}$ The lymph nodes of the radical neck-dissected specimens were checked for the absence or presence of metastases both in the gross and histopathologically stained slides. The case histories, including age, sex, the past medical history, the duration of the disease, and habits, were all recorded.

\section{Statistical analysis}

The data was tabulated and statistical tests were done using the SPSS for Windows v. 16.0 software (SPSS, Inc., Chicago, USA). Categorical data were presented as percentages. The reliability of the ratings by 3 pathologists using Bryne's modified grading system was measured with Cohen's kappa coefficient. Fisher's exact test was applied to assess the relation between Broder's modified grading system and Bryne's modified grading system with regard to cervical lymph node metastasis. The results were considered statistically significant at a $p$-value $<0.05$. 


\section{Results}

Reviewing a total of 62 cases of OSCC reported from 2012 to 2014, 30 cases of OSCC of the tongue (Fig. 1) treated with radical neck dissection that met the inclusion criteria were diagnosed histopathologically according to the tumor, node and metastasis (TNM) classification, Broder's modified system and Bryne's modified grading.

Of the 30 cases, 17 (56.7\%) were males and 13 (43.3\%) were females. The mean age was 54.9 years, ranging from 17 to 73 years. The mean age among the males was 55.4 years and among the females -54.5 years.

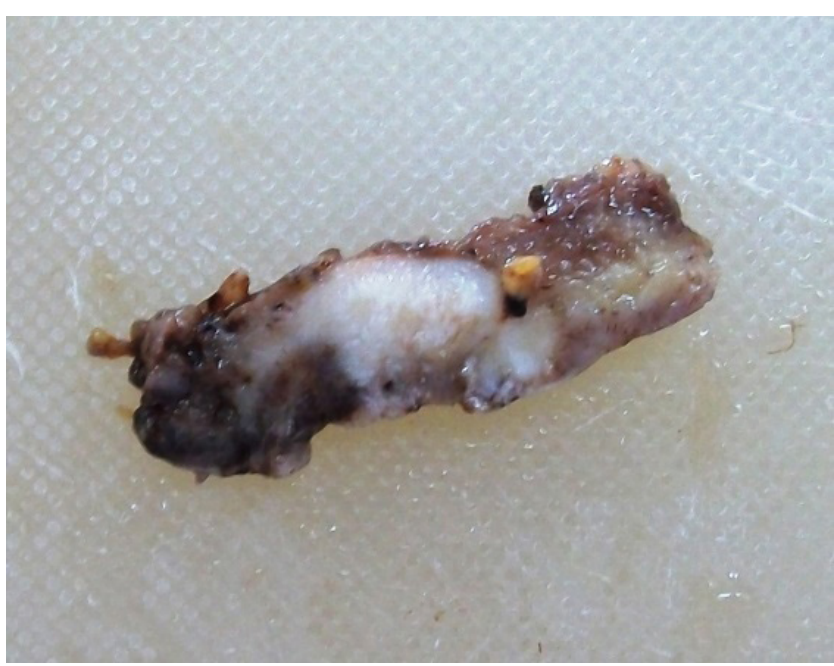

Fig. 1. Gross pathology of a metastatic lymph node

Table 1. Distribution of the study subjects according to the lymph node status

\begin{tabular}{|l|c|c|}
\hline Lymph node status & $\begin{array}{c}\text { Frequency } \\
n\end{array}$ & $\begin{array}{c}\text { Frequency } \\
\%\end{array}$ \\
\hline Metastatic & 14 & 46.7 \\
Non-metastatic & 16 & 53.3 \\
Total & 30 & 100.0 \\
\hline
\end{tabular}

Table 2. Relationship between the tumor size and the lymph node status

\begin{tabular}{|l|c|c|c|c|} 
Tumor size & $\begin{array}{c}\text { Metastatic } \\
\text { group } \\
n(\%)\end{array}$ & $\begin{array}{c}\text { Non-metastatic } \\
\text { group } \\
n(\%)\end{array}$ & $\begin{array}{c}\text { Total } \\
n(\%)\end{array}$ & $p$-value \\
\hline T1 $(<2 \mathrm{~cm})$ & $6(42.9)$ & $7(43.8)$ & $13(43.3)$ & \\
T2 $(2-4 \mathrm{~cm})$ & $3(21.4)$ & $5(31.2)$ & $8(26.7)$ & 0.813 \\
T3 $(>4 \mathrm{~cm})$ & $5(35.7)$ & $4(25.0)$ & $9(30.0)$ & \\
Total $(\mathrm{N}=30)$ & $14(46.7)$ & $16(53.3)$ & $30(100)$ & \\
\hline
\end{tabular}

Fisher's exact test.
Lymph node metastases were observed in 14 (46.7\%) of the cases whereas 16 (53.3\%) were free of metastases (Table 1). In the metastatic group, $6(42.9 \%)$ of the cases were males and $8(57.1 \%)$ were females, while in the non-metastatic group, $11(68.8 \%)$ were males and $5(31.2 \%)$ were females.

The duration of the disease in all 30 cases ranged from 1 to 36 months, with an average of 5.8 months. The difference in the mean duration of the disease between the metastatic and non-metastatic groups was not significant, indicating a lack of any correlation between disease duration and lymph node metastasis.

Among the males, 12 (70.6\%) were habitual users of tobacco (chewing, smoking) and/or alcohol. Neither of these habits was noted among the women.

The tumor diameters ranged from $0.6 \mathrm{~cm}$ to $6 \mathrm{~cm}$, with an average of $3.3 \mathrm{~cm}$. With regard to the primary tumor size, of the 14 cases analyzed in the metastatic group, 6 (42.9\%) were T1 tumors, $3(21.4 \%)$ were T2 tumors and $5(35.7 \%)$ were T3 tumors, while of the 16 cases in the non-metastatic group, 7 (43.8\%) were T1, 5 (31.2\%) were T2 and $4(25.0 \%)$ were T3. There was no statistically significant relationship between the tumor size and lymph node metastasis (Table 2).

With regard to Broder's modified grading system, 24(80\%) of the cases were well-differentiated, 5 (16.7\%) were moderate and 1 (3.3\%) was poorly differentiated (Fig. 2). The relationship between the modified version of Broder's grading system and lymph node metastasis is presented in Table 3. Among the 14 cases in the metastatic group, 10 (71.5\%) were well-differentiated, $3(21.4 \%)$ were moderate and 1 (7.1\%)
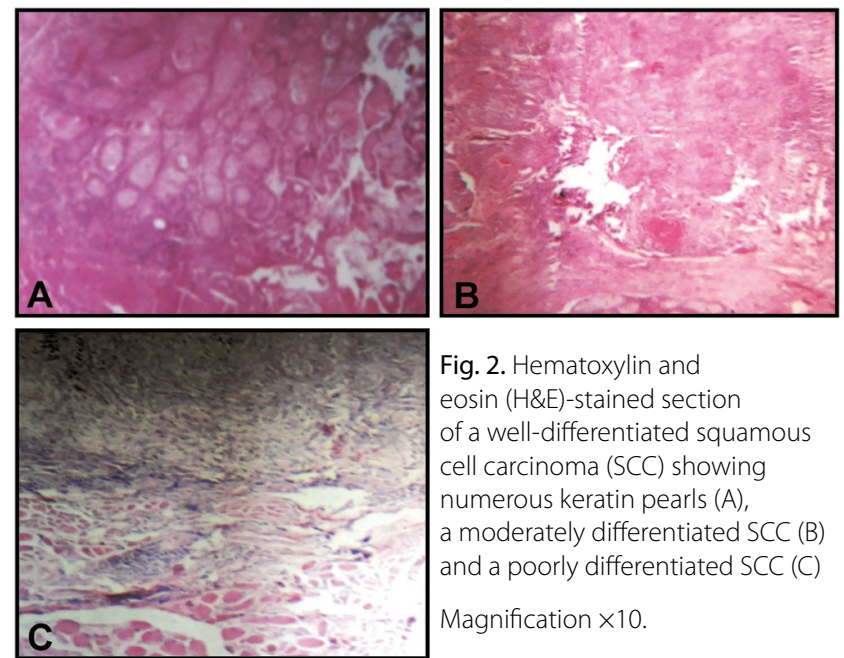

Fig. 2. Hematoxylin and eosin (H\&E)-stained section of a well-differentiated squamous cell carcinoma (SCC) showing numerous keratin pearls $(A)$, a moderately differentiated SCC (B) and a poorly differentiated SCC (C) Magnification $\times 10$

Table 3. Relationship between Broder's modified grading system and the lymph node status

\begin{tabular}{|l|c|c|c|}
\multicolumn{1}{|c|}{$\begin{array}{c}\text { Broder's modified } \\
\text { grading system }\end{array}$} & $\begin{array}{c}\text { Metastatic group } \\
n(\%)\end{array}$ & $\begin{array}{c}\text { Total } \\
n(\%)\end{array}$ \\
\hline Well-differentiated SCC & $10(71.5)$ & $14(87.5)$ & $24(80.0)$ \\
Moderately differentiated SCC & $3(21.4)$ & $2(12.5)$ & $5(16.7)$ \\
Poorly differentiated SCC & $1(7.1)$ & $0(0)$ & $1(3.3)$ \\
Total $(N=30)$ & $14(46.7)$ & $16(53.3)$ & $30(100)$ \\
\hline
\end{tabular}

SCC - squamous cell carcinoma; Fisher's exact test. 
was poorly differentiated; among the 16 non-metastatic cases, 14 (87.5\%) were well-differentiated and 2 (12.5\%) were moderately differentiated. The statistical analysis failed to detect any significant relationship between Broder's modified grading system and lymph node metastasis.

Bryne's modified grading system examines 4 morphological features: the rate of keratinization, polymorphism in the cell nucleus, the pattern of invasion, and the response from the host. These parameters are assessed in the most invasive margins of the tumor. Scores range from 1 to 4 . The modified version of Bryne's ITF grading was used by 3 pathologists to score all the cases included in the study and there was a strong agreement (0.81) among the scorers. Of the 30 cases, 14 (46.7\%) were classified as grade I, $13(43.3 \%)$ as grade II and $3(10 \%)$ as grade III.

Among the 14 cases in the metastasizing group, 2 (14.3\%) were classified as grade I, $9(64.3 \%)$ as grade II and 3 (21.4\%) as grade III. Among the 16 non-metastasizing cases, 12 (75\%) were classified as grade I and 4 (25\%) as grade II (Fig. 3-5, Table 4). Bryne's modified grading system showed a significant association $(p=0.001)$ with lymph node metastasis (Table 4). It is evident from the comparison of the 2 grading systems that Bryne's ITF grading classification correlates more strongly with lymph node metastasis than Broder's system does (Fig. 6).
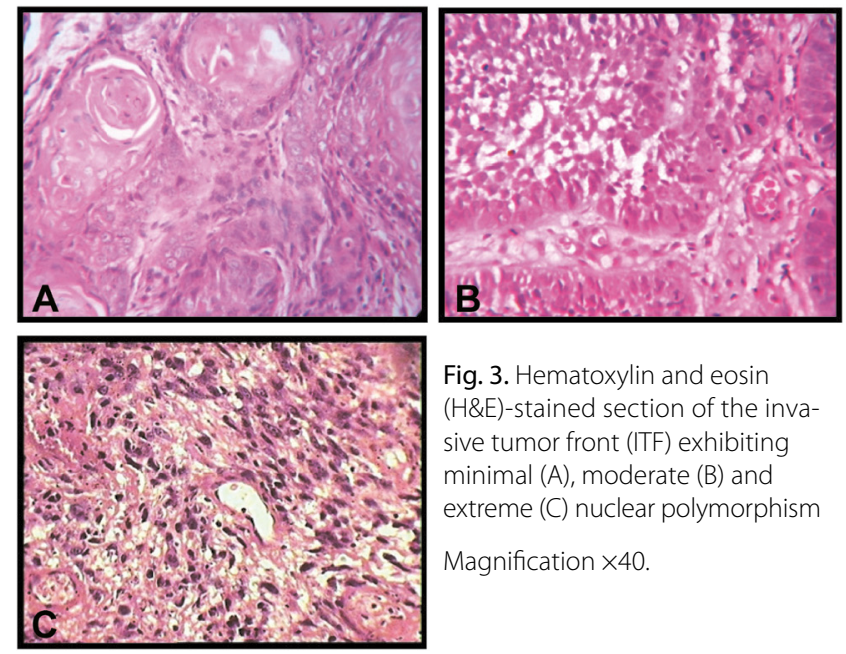

Fig. 3. Hematoxylin and eosin

(H\&E)-stained section of the invasive tumor front (ITF) exhibiting minimal (A), moderate (B) and extreme $(C)$ nuclear polymorphism Magnification $\times 40$.
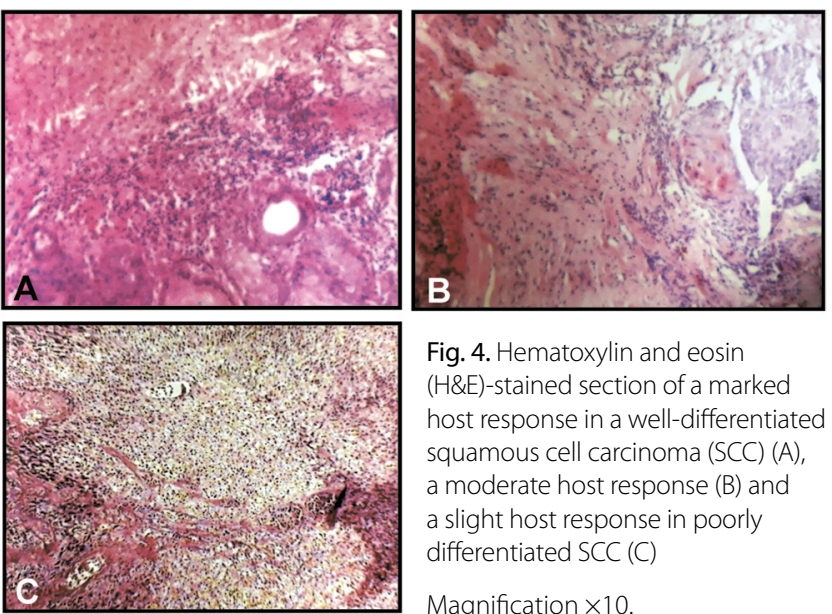

Fig. 4. Hematoxylin and eosin (H\&E)-stained section of a marked host response in a well-differentiated squamous cell carcinoma (SCC) (A), a moderate host response (B) and a slight host response in poorly differentiated SCC (C)

Magnification $\times 10$.
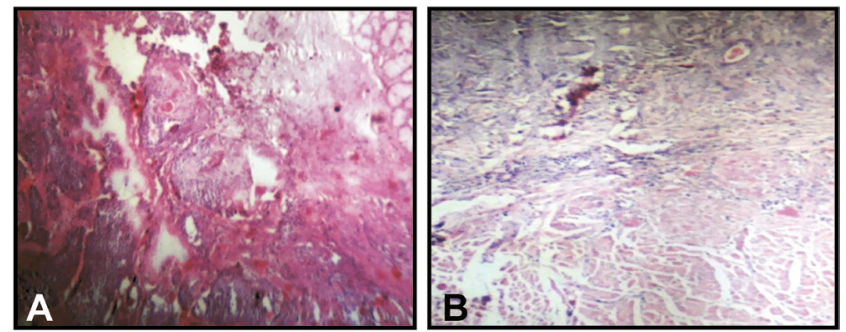

Fig. 5. Hematoxylin and eosin (H\&E)-stained section of the invasive tumor front (ITF) exhibiting infiltrating solid cords or bands (A) and small cords of infiltrating cells with muscle invasion (B)

Magnification $\times 10$.

Table 4. Relationship between Bryne's modified grading system and the lymph node status

\begin{tabular}{|l|c|c|c|c|}
\hline $\begin{array}{l}\text { Bryne's modified } \\
\text { grading system }\end{array}$ & $\begin{array}{c}\text { Metastatic } \\
\text { group } \\
n(\%)\end{array}$ & $\begin{array}{c}\text { Non-metastatic } \\
\text { group } \\
n(\%)\end{array}$ & $\begin{array}{r}\text { Total } \\
n(\%)\end{array}$ & $p$-value \\
\hline Grade I & $2(14.3)$ & $12(75.0)$ & $14(46.7)$ & \\
Grade II & $9(64.3)$ & $4(25.0)$ & $13(43.3)$ & $0.001^{*}$ \\
Grade III & $3(21.4)$ & $0(0)$ & $3(10.0)$ & \\
Total $(N=30)$ & $14(46.7)$ & $16(53.3)$ & $30(100)$ & \\
\hline
\end{tabular}

* statistically significant; Fisher's exact test.

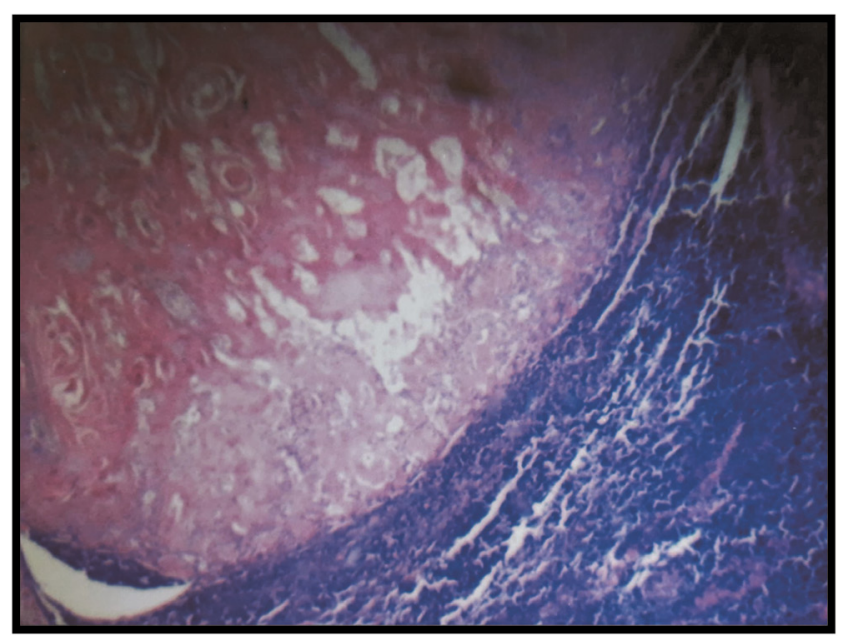

Fig. 6. Hematoxylin and eosin (H\&E)-stained section of a lymph node metastasis showing keratin formation

Magnification $\times 10$.

\section{Discussion}

Oral cancer is the most common type of cancer in India, with a total cancer mortality of $50-70 \%$. In this study, among the 30 cases of OSCC of the tongue, males comprised $56.7 \%$. Many studies have shown the prevalence of OSCC in males..$^{5,9,10} \mathrm{~A}$ high rate of OSCC among males could be related to a high rate of tobacco use (chewing and smoking) among them. This is relevant in the present study, where habitual tobacco chewing and smoking, and/or alcohol consumption were prevalent among the males $(70.6 \%)$. 
Invasion and growth into surrounding tissues are known to characterize OSCC. Metastases are considered the most challenging feature of cancer progression. They generally signify limited survival rates and ineffective therapy. ${ }^{11}$ The most important factor for prognosis in head and neck SCC is cervical lymph node metastasis. ${ }^{12} \mathrm{With}$ the development of carcinoma in the oral cavity, the cancer may spread to regional lymph nodes through the lymphatic drainage system. This process is further increased by the poorly differentiated behavior of these tumors. This determines the survival rate of patients, as in the case of carcinomas that have spread to regional lymph nodes, there is a 5-year survival rate, which is half of that observed for cancers in the oral cavity that have not metastasized.

Various studies have reported a significant relationship between the degree of histologic differentiation and the occurrence of lymph node metastasis in SCC of the head and neck region. ${ }^{13-15}$

Broder initiated the grading of cancer in 1920 with a quantitative method based on the proportion of differentiated cells to undifferentiated cells. Despite slight modifications in Broder's system of classification of SCC, limitations remain when prognosis and the choice of treatment are considered. It may be due to the heterogeneity of the cell population present in SCC tumors.

Although Broder's system has been used for many years, a lack of association between the system and prognosis has been mentioned in the literature. However, in their study, Odell et al. found an association between Broder's grading system and local recurrence and metastasis. ${ }^{16}$ On the other hand, both Dissanayake and Doshi et al. failed to observe any relationship between Broder's grading system and lymph node metastasis. ${ }^{5,10}$ A study by Jamadar et al. on 20 cases of OSCC showed no correlation of this grading system with the lymph node status. ${ }^{17}$ The present study also failed to observe any association between Broder's modified grading system and lymph node metastasis.

As a result, the need for a new system of grading has been felt. Jakobsson et al. extended Broder's 2-factor grading system to multifactorial parameters, such as the structure of the tumor, the ability to differentiate, nuclear polymorphism, and the number of mitoses. ${ }^{18}$ Following this, many other grading systems have been developed and improved over a few decades by many researchers. ${ }^{13,17}$

Bryne et al. took into consideration the fact that in malignancies, there are heterogeneous tumor cells. ${ }^{19}$ They observed that cells in the deep invasive margin were less differentiated than those in the superficial part of the tumor. ${ }^{19}$ The histologic grading of the superficial areas of the tumor may not give the accurate diagnosis of its aggressive behavior and accurate prognosis for the tumor.

Bryne et al. modified Anneroth's multifactorial grading system. ${ }^{8}$ In this modified system, cells in the deep invasive margin of the tumor were graded. The invasion stages and the mitotic count were removed from the system, increasing the reproducibility of the grading system.
The mitotic count, which was used as a marker for prognosis, was dependent on factors such as tumor heterogeneity, disagreement among the observers and variations in the high-power field of the microscopes used for the study. The validity of the parameter was also dependent on a very low mitotic count in the deep invasive region of the tumor as compared to more solid tumor areas.

The malignancy grading of the deep invasive margins of OSCCs based on various factors was introduced by Bryne et al., and has proved to be of high prognostic value. ${ }^{8,21}$ In the present study, this system correlated significantly with lymph node metastasis.

Studies by Bryne et al. as well as Monevska et al. reported a strong association between the total malignancy grade of several pathologic parameters and prognosis in OSCC. ${ }^{8,21}$ A study by Doshi et al. showed a significant association $(p=0.05)$ between Bryne's grading system and lymph node metastasis, which closely matches the results of the present study. ${ }^{10}$ Furthermore, a study by Khwaja et al. identified the ITF grading as the most important predictive factor for cervical lymph node metastasis, and also suggested that the ITF grading could be taken into consideration when selecting the most appropriate treatment approach. ${ }^{22}$

Bryne's grading system has shown to be prognostic, and also to have good inter- and intra-observer reliability. ${ }^{23}$ In the present study, inter-observer reliability was $r=0.81$, which revealed a strong agreement among the 3 pathologists grading the tumors.

A frequent lack of inter-observer agreement in the process of scoring many parameters is a major problem that limits the clinical usefulness of histologic grading. ${ }^{23}$ Biopsies do not represent the whole tumor, but are the only tissue samples available for histologic evaluation, which limits the current study. Therefore, specific criteria need to be set for selecting a representative tumor tissue to conduct histologic grading.

\section{Conclusions}

In the present study, the modified version of Bryne's grading system showed a statistically significant correlation with lymph node metastasis, which is compatible with the results of previous studies. ${ }^{5,10,22,24}$ Histopathological grading is one of the factors used to make prognosis for OSCCs. The established factors for predicting the biological behavior of these tumors are not very well substantiated. However, pathologists have observed that cells in the most invasive parts of a malignant tumor differ substantially from those in the superficial areas of the tumor. This has led to recognizing the significance of the structural and functional features of the most advanced part of carcinomas - ITF - in determining the biological aggressiveness of the tumor. The study indicates that Bryne's modified grading system at the tumor/tissue interface can be taken as a diagnostic factor and prognosis for lymph node metastasis. 


\section{ORCID iDs}

Ranjith Shetty (D) https://orcid.org/0000-0001-7932-3467

\section{References}

1. Bello IO, Soini Y, Salo T. Prognostic evaluation of oral tongue cancer: Means, markers and perspectives (II). Oral Oncol. 2010;46(9):636-643.

2. Nicoara M, Bain K, Patel R, Jaikaran O, Hingorani A, Asher E. Malignant transformation of non-healing ulcer-basal cell carcinoma. Ann Vasc Surg. 2020;S0890-5096(20)30156-4.

3. Cho JK, Hyun SH, Choi N, et al. Significance of lymph node metastasis in cancer dissemination of head and neck cancer. Translat Oncol. 2015;8(2):119-125.

4. Akhter M, Hossain S, Rahman QB, Molla MR. A study on histological grading of oral squamous cell carcinoma and its co-relationship with regional metastasis. J Oral Maxillofac Pathol. 2011;15(2):168-176.

5. Dissanayake U. Malignancy grading of invasive fronts of oral squamous cell carcinomas: Correlation with overall survival. Transl Res Oral Oncol. 2017;2(1):1-8.

6. Chang YC, Nieh S, Chen SF, Jao SW, Lin YL, Fu E. Invasive pattern grading score designed as an independent prognostic indicator in oral squamous cell carcinoma. Histopathology. 2010;57(2):295-303.

7. Broder AC. Carcinoma of the mouth: Types and degrees of malignancy. Am J Roentgenol Radium Ther Nucl Med. 1927;17:90-93.

8. Bryne M, Koppang HS, Lilleng R, Kjaerheim A. Malignancy grading of the deep invasive margins of oral squamous cell carcinomas has high prognostic value. J Pathol. 1992;166(4):375-381.

9. Singh MP, Kumar V, Agarwal A, Kumar R, Bhatt MLB, Misra S. Clinicoepidemiological study of oral squamous cell carcinoma: A tertiary care centre study in North India. J Oral Biol Craniofac Res. 2016;6(1):31-34.

10. Doshi NP, Shah SA, Patel KB, Jhabuawala MF. Histological grading of oral cancer: A comparison of different systems and their relation to lymph node metastasis. Nat J Community Med. 2011;2(1):136-142.

11. Markopoulos AK. Current aspects on oral squamous cell carcinoma. Open Dent J. 2012;6:126-130.

12. Burusapat C, Jarungroongruangchai W, Charoenpitakchai M. Prognostic factors of cervical node status in head and neck squamous cell carcinoma. World J Surg Oncol. 2015;13(1):51-62.

13. Jadhav KB, Gupta N. Clinicopathological prognostic implicators of oral squamous cell carcinoma: Need to understand and revise. N Am J Med Sci. 2013;5(12):671-679.

14. Kapoor C, Vaidya S, Wadhwan V, Malik S. Lymph node metastasis: A bearing on prognosis in squamous cell carcinoma. Indian J Cancer. 2015;52(3):417-424.

15. De Silva RK, Siriwardena BSMS, Samaranayaka A, Abeyasinghe WAMUL, Tilakaratne WM. A model to predict nodal metastasis in patients with oral squamous cell carcinoma. PloS One. 2018;13(8):e0201755.

16. Odell EW, Jani P, Ahluwalia SM, Hibbert J, Levison DA, Morgan PR. The prognostic value of individual histologic grading parameters in small lingual squamous cell carcinomas. The importance of the pattern of invasion. Cancer. 1994;74(3):789-794.

17. Jamadar S, Narayan TV, Shreedhar B, Mohanty L, Shenoy S. Comparative study of various grading systems in oral squamous cell carcinoma and their value in predicting lymph node metastasis. Indian J Dent Res. 2014;25(3):357-363.

18. Jakobsson PA, Eneroth CM, Killander D, Moberger G, Mårtensson B. Histologic classification and grading of malignancy in carcinoma of the larynx. Acta Radiol Ther Phys Biol. 1973;12(1):1-8.

19. Bryne M, Koppang HS, Lilleng R, Stene T, Bang G, Dabelsteen E. New malignancy grading is a better prognostic indicator than Broder's grading in oral squamous cell carcinomas. J Oral Pathol Med. 1989;18(8):432-437.

20. Sharma M, Sah P, Sharma SS, Radhakrishnan R. Molecular changes in invasive front of oral cancer. J Oral Maxillofac Pathol. 2013;17(2):240-247.

21. Monevska DP, Janevska V, Naumovski S, et al. Multiple pathohistological parameters influencing prognosis and survival of oral cancer patients. Pril (Makedon Akad Nauk Umet Odd Med Nauki). 2013;34(2):169-174.
22. Khwaja T, Tayaar AS, Acharya S, Bhushan J, Muddapur MV. Pattern of invasion as a factor in determining lymph node metastasis in oral squamous cell carcinoma. J Cancer Res Ther. 2018;14(2):382-387.

23. Bryne M, Nielsen K, Koppang HS, Dabelsteen E. Reproducibility of two malignancy grading systems with reportedly prognostic value for oral cancer patients. J Oral Pathol Med. 1991;20(8):369-372.

24. Nadaf A, Bavle RM, Soumya M, D'mello S, Kuriakose MA, Govindan $S$. Analysis of the invasive edge in primary and secondary oral squamous cell carcinoma: An independent prognostic marker: A retrospective study. J Oral Maxillofac Pathol. 2016;20(2):239-245. 